doctors requested an autopsy themselves and most were successful in obtaining permission from the relatives. The party also recommends that "the autopsy or at least a demonstration of the major findings should be attended by a member of the clinical team."

Autopsy findings differ noticeably from clinical diagnoses in $10 \%$ of cases. As awareness of clinical errors increases both within the profession and in the general public, feedback from postmortem examina- tions to clinicians responsible for patient care must be given.

Contributors: JNL is the guarantor.

Funding: None.

Competing interests: None declared.

Joint Working Party of representatives from the Royal College of Pathologists, Royal College of Physicians of London and the Royal College of Surgeons. Report of the Joint Working Party on the Autopsy and Audit. London: Royal College of Pathologists, 1991.

(Accepted 19 February 2001)

\title{
Training in basic and advanced life support in UK medical schools: questionnaire survey
}

\author{
P S Phillips, J P Nolan
}

Faculty of Medicine, Southampton University,

Southampton

General Hospital,

Southampton

SO16 6YD

P S Phillips

medical student

Department of Anaesthesia and Intensive Care Medicine, Royal United Hospital,

Bath BA1 3NG

J P Nolan

consultant

Correspondence to: P S Phillips

seamusphillips@

hotmail.com

BMJ 2001;323:22-3
Newly qualified doctors are expected to take part in resuscitation from their first day. The General Medical Council states that preregistration house officers should have training in basic life support before they begin their first post and that they should receive advanced life support training during the first year. ${ }^{1}$ However, it places no obligation on medical schools or trusts to provide a defined standard of resuscitation training. The Royal College of Physicians has stated that advanced life support should be taught in the undergraduate course and that preregistration house officers should be "capable of instituting" advanced life support. ${ }^{2}$ A recent unpublished survey found that only four out of 16 responding medical schools fulfilled the royal college's recommendations. ${ }^{3}$ We decided to assess the situation in more depth.

\section{Method and results}

A survey was devised in consultation with BMA student representatives of all medical schools in the United Kingdom, using an internet discussion forum. This survey was completed by all representatives in consultation with their medical schools. Additional information was obtained from undergraduate deans. Basic life support training was defined as training in cardiopulmonary resuscitation using a manikin. Uncertificated advanced life support training was defined as compulsory training in the airway-breathing-circulation approach, basic training in the use of a defibrillator, and an introduction to other cardiac rhythms and the use of drugs. Uncertificated courses lasted either half a day or one day. A certificated Resuscitation Council (UK) advanced life support course is a standardised course lasting two or three days with a pass or fail decision at the end.

Completed questionnaires were received from 23 of the 27 schools surveyed. Results were sent to the deans of all 27 medical schools. Replies were received from 10 schools, including one school that had not replied to the initial survey. The other three schools failed to respond both to postal reminders sent two months after the initial survey and to the mailings sent to the deans. The results are summarised in the table .

\section{Comments}

The results show that most medical schools provide some form of compulsory advanced life support training. However, two (8\%) of the medical schools do not provide any compulsory training, and it is possible that the three schools that failed to respond also provide no training. The extent of training in the remaining schools is variable. This indicates considerable room for improvement.

Doctors still seem to be expected to learn resuscitation skills in the clinical setting, where there is little opportunity to correct poor technique. Once students become preregistration house officers their time for training is limited, and they have no allocated study budget until after the preregistration year. Those who attend advanced life support courses usually do so in their own time and with their own money. As a result, most preregistration house officers receive from the trusts that employ them only non-standardised advanced life support revision courses lasting half a day.

Given this situation, and the fact that many junior doctors are not competent in carrying out effective cardiopulmonary resuscitation, ${ }^{45}$ perhaps training in advanced life support should become a standardised and mandatory component of all medical school undergraduate curriculums.

A fundamental question is what training a preregistration house officer needs to be "capable of instituting" advanced life support, as specified by the Royal College of Physicians. Three schools in our survey put their students through a formal advanced life

Number and percentage of medical schools (replies received from 24 of 27 surveyed) providing various types of life support training

\begin{tabular}{lc} 
Type of training provided & No (\%) \\
\hline Compulsory basic life support training & $24(100)$ \\
\hline $\begin{array}{l}\text { Compulsory uncertificated advanced life support training } \\
\text { Compulsory certificated two or three day advanced life support } \\
\text { course }\end{array}$ & $3(79)$ \\
\hline Some form of advanced life support training & $22(92)$ \\
\hline Give crash bleeps to students &
\end{tabular}

*Only 21 schools replied to this question. 
support course lasting two to three days, but there is no evidence that this is any better or worse than an informal course lasting one day or less. More work needs to be done in evaluating the right level of training for medical students. In 2001 the Resuscitation Council (UK) will launch an immediate life support course lasting one day; this may provide optimal standardised resuscitation training for medical students.

The members of the BMA Medical Students Committee for 1998-9 were Lizz Corps (Chair), Malcolm Chambers, Georgina Burnham, Peter Hale, Simon Korn, Mike Moneypenny, Sian Stephens, Nicola Littlewood, Helen Neary, Emily Craft, Bushra Alam, Michael Urdang, Anusa Sabanathan, Parham Azarbod, Sarah Snowden, Katie Ward, Pedram Azarbod, Nick Jenkins, Joseph Foottit, Zoe Silverstone, Jennifer Campbell, Saul Rajak, Richard Graham, Keira Lindsay, Victoria McCormack, Jason Coventry, Séamus Phillips, Mark Haynes, Remy McConvey, Adele McKenna, Dan Atkinson, Mellissa Robson, Hannah
Seymour, David Heylings, Rachel Lindlay, Andrew Jinks, and Gemma Hale

Contributors: PSP designed the questionnaire and collated the results. JPN wrote to post-graduate deans. Both JPN and PSP wrote the paper, and both will act as guarantors.

Funding: The resources of the BMA Medical Students Committee were used to distribute and collate questionnaires.

Competing interests: JPN is chair of the Advanced Life Support Sub-committee of the Resuscitation Council (UK).

General Medical Council. The new doctor: recommendations on general clini cal training made under Section 5 of the Medical Act 1983. London: GMC, 1997

2 Royal College of Physicians of London. Resuscitation from cardiopulmonary arrest. J R Coll Physicians Lond 1987;21:175-182.

3 Perkins GD, Hulme J, Shore HR, Bion J. Basic life support training for health care students. Resuscitation 1999;41:19-23

4 Skinner D, Camm A, Miles S. Cardiopulmonary skills of preregistration house officers. BMJ 1985;290:1549-50.

5 Casey WF. Cardiopulmonary resuscitation: a survey among junior hospital doctors. JR Soc Med 1984;77:921-4.

(Accepted 17 January 2001)

\section{Drug points}

\section{Cholestatic hepatitis in association with celecoxib}

J P O'Beirne, S R Cairns, Digestive Disease Centre, Royal Sussex County Hospital, Brighton BN2 5BE

Non-steroidal anti-inflammatory drugs, particularly diclofenac sodium, have been associated with serious hepatotoxicity. ${ }^{1}$ Recently, cyclo-oxygenase- 2 selective nonsteroidal anti-inflammatory drug inhibitors have become popular for the treatment of arthritic conditions, mainly because of their safer profile for gastrointestinal side effects. ${ }^{2}$ Celecoxib (Celebrex; Searle) is one such drug, licensed for the treatment of rheumatoid arthritis and osteoarthritis. We report a case of serious hepatotoxicity associated with celecoxib.

A 54 year old woman developed sacroiliac pain. She consulted her general practitioner, who prescribed celecoxib $200 \mathrm{mg}$ daily. After four days her pain resolved and she developed generalised pruritus. When celecoxib was discontinued the pruritus resolved.

A week later the pain returned and celecoxib was restarted. Two days later the patient developed dark urine and increasing pruritus. Five days later she developed jaundice, and blood tests showed an aspartate transaminase concentration of $1650 \mathrm{IU} / 1$ (reference range $10-40$ IU/1), alkaline phosphatase 232 IU/1 (25-115 IU/1), and bilirubin $123 \mu \mathrm{mol} / 1(5-20 \mu \mathrm{mol} / \mathrm{l})$. She was also taking isphagula husk (Fybogel; Reckitt and Colman) and alverine citrate (Spasmonal; Norgine), which she had taken for many months, and hormone replacement therapy (six monthly implants of oestradiol with $100 \mathrm{mg}$ of testosterone), which she had received for four years. She was referred to us for further management.

She had no risk factors for viral hepatitis, and examination was normal apart from noticeable icterus. All drugs were withdrawn and relevant blood tests were performed. We excluded viral and autoimmune hepatitis by blood tests. Her eosinophil count was raised at $0.8 \times 10^{6} / 1$. A hepatic ultrasonogram appeared normal.

On withdrawal of celecoxib her liver function tests improved (figure) and her symptoms resolved. The temporal relation between ingestion of the drug and hepatotoxicity strongly suggested an association between celecoxib and liver damage. A yellow card was submitted to the Committee on Safety of Medicines.

In a review of controlled clinical trials involving 7400 patients, hepatic dysfunction occurred in $0.8 \%$ of those treated with celecoxib compared with $0.9 \%$ treated with placebo and 3.7\% treated with diclofenac sodium. No patient treated with celecoxib, however, had increases of alkaline phosphatase concentrations greater than eight times normal.

Nimesulide, another non-steroidal anti-inflammatory drug with cyclo-oxygenase- 2 selectivity, has been reported to cause fulminant hepatic failure, ${ }^{4}$ and celecoxib has been associated with hepatitis and pancreatitis. ${ }^{5}$ To our knowledge severe cholestatic hepatitis has not been reported in association with celecoxib.

Physicians should be aware that, despite a better safety profile for gastrointestinal side effects than conventional non-steroidal anti-inflammatory drugs, celecoxib may still be associated with severe hepatotoxicity. Celecoxib should be stopped if the results of liver function tests are abnormal.

Competing interests: None declared.

1 Iveson TJ, Ryley NG, Kelly PM, Trowell JM, McGee JO, Chapman RW. Diclofenac associated hepatitis. J Hepatol 1990;10:85-9.

2 Silverstein FE, Faich G, Goldstein JL, Simon LS, Pincus T, Whelton A, et al. Gastrointestinal toxicity with celecoxib vs nonsteroidal antiinflammatory drugs for osteoarthritis and rheumatoid arthritis: the CLASS study: a randomized controlled trial. Celecoxib long-term arthritis safety study. JAMA 2000;284:1247-55.

3 Maddrey WC, Maurath CJ, Verburg KM, Geis GS. The hepatic safety of and tolerability of the novel cyclooxygenase-2 inhibitor celecoxib. Am Ther 2000;7:153-8.

4 McCormick PA, Kennedy F, Curry M, Traynor O. COX-2 inhibitor and fulminant hepatic failure. Lancet 1999;352:353.

5 Carrillo-Jimenez R, Nurnberger M, Celecoxib-induced acute pancreatitis and hepatitis. Arch Intern Med 2000;170:553-4.
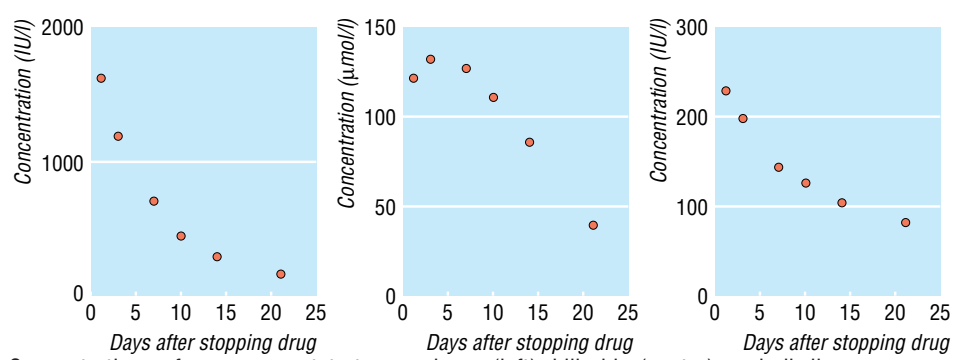

Concentrations of serum aspartate transaminase (left), bilirubin (centre), and alkaline

phosphatase (right) after celecoxib was stopped 